\title{
GEOGRAPHICAL INFORMATION ANALYSIS OF TSUNAMI FLOODED AREA BY THE GREAT EAST JAPAN EARTHQUAKE USING MOBILE MAPPING SYSTEM
}

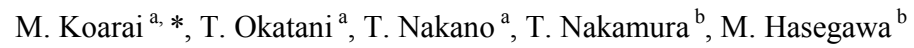 \\ ${ }^{a}$ Geography and Crustal Dynamics Research Center, Geospatial Information Authority of Japan, Kitasato1, Tsukuba, \\ Ibaraki, 305-0811 Japan - (koarai, okatani, t-nakano)@gsi.go.jp \\ ${ }^{\mathrm{b}}$ Dept. of Applied Geography, Geospatial Information Authority of Japan, Kitasato1, Tsukuba, Ibaraki, 305-0811 Japan \\ -(nakamura,gaku)@gsi.go.jp
}

Commission VIII, WG VIII/1

KEY WORDS: The Great East Japan Earthquake, Tsunami damage, Flood depth, Mobile Mapping System, landform classification, DEMs, Land use

\begin{abstract}
:
The great earthquake occurred in Tohoku District, Japan on 11th March, 2011. This earthquake is named "the 2011 off the Pacific coast of Tohoku Earthquake", and the damage by this earthquake is named "the Great East Japan Earthquake". About twenty thousand people were killed or lost by the tsunami of this earthquake, and large area was flooded and a large number of buildings were destroyed by the tsunami.

The Geospatial Information Authority of Japan (GSI) has provided the data of tsunami flooded area interpreted from aerial photos taken just after the great earthquake. This is fundamental data of tsunami damage and very useful for consideration of reconstruction planning of tsunami damaged area.

The authors analyzed the relationship among land use, landform classification, DEMs data flooded depth of the tsunami flooded area by the Great East Japan Earthquake in the Sendai Plain using GIS. Land use data is 100 meter grid data of National Land Information Data by the Ministry of Land, Infrastructure, Transportation and Tourism (MLIT). Landform classification data is vector data of Land Condition Map produced by GSI. DEMs data are 5 meters grid data measured with LiDAR by GSI after earthquake. Especially, the authors noticed the relationship between tsunami hazard damage and flooded depth. The authors divided tsunami damage into three categories by interpreting aerial photos; first is the completely destroyed area where almost wooden buildings were lost, second is the heavily damaged area where a large number of houses were destroyed by the tsunami, and third is the flooded only area where houses were less destroyed. The flooded depth was measured by photogrammetric method using digital image taken by Mobile Mapping System (MMS).

The result of these geographic analyses show the distribution of tsunami damage level is as follows: 1) The completely destroyed area was located within $1 \mathrm{~km}$ area from the coastline, flooded depth of this area is over $4 \mathrm{~m}$, and no relationship between damaged area and landform classification. 2) The heavily damaged area was observed up to 3 or $4 \mathrm{~km}$ from the coastline. Flooded depth of this area is over $1.5 \mathrm{~m}$, and there is a good relationship between damaged area and height of DEMs. 3) The flood only area was observed up to 4 or $5 \mathrm{~km}$ from the coastline. Flooded depth of this area was less than $1.5 \mathrm{~m}$, and there is a good relationship between damaged area and landform. For instance, a certain area in valley plain or flooded plain was not affected by the tsunami, even though an area with almost the same height in coastal plain or delta was flooded. These results mean that it is important for tsunami disaster management to consider not only DEMs but also landform classification.
\end{abstract}

\section{INTRODUCTION}

The great earthquake occurred in Tohoku District, Japan on 11th March, 2011. This earthquake is named "the 2011 off the Pacific coast of Tohoku Earthquake", and the damage by this earthquake is named "the Great East Japan Earthquake". About twenty thousand people were killed or lost by the tsunami of this earthquake, and large area was flooded and a large number of buildings were destroyed by the tsunami.

The Geospatial Information Authority of Japan (GSI) has provided the data of tsunami flooded area interpreted from aerial photos taken just after the great earthquake. This data is fundamental data of tsunami damage and very useful for consideration of reconstruction planning of tsunami damaged area. It is important for the planning of expected tsunami hazard area to clarify the geographical characteristics such as landform and land use of tsunami flooded area.

The authors did overlay analysis about the relationship between tsunami damage and geographical characteristics of tsunami flooded area by the Great East Japan Earthquake in the Sendai Plain using GIS. Land use data is 100 meter grid data of National Land Information Data by the Ministry of Land, Infrastructure, Transportation and Tourism (MLIT). Landform classification data is vector data of Land Condition Map produced by GSI. DEMs data are 5 meters grid data measured with airborne laser survey data (LiDAR data) by GSI after earthquake. Especially, the authors noticed the relationship between tsunami hazard damage and flooded depth.

In this presentation, the authors introduce the result of these overlay analysis and geographical characteristics of tsunami flooded area.

\footnotetext{
* Corresponding author.
} 


\section{USED GEOSPATIAL DATA}

\subsection{Landform classification}

Landform classification data is vector data of Land Condition Map "Sendai" and "Iwanuma" produced by GSI. As there is no data of Land Condition Map of "Kakuda" area, the authors had produced landform classification data of "Kakuda" area by the interpretation of aerial photo with scale of $1 / 10,000$ taken by GSI in 1961. Landform classification was divided into fourteen categories, such as mountain slope, unstable slope, terrace or table land, talus, alluvial fan, natural levee or sand dune or sand bar, dent or shallow valley, valley plain or flood plain, coastal plain or delta, back marsh, former river bed, frequently flooded area, water and artificial deformed area.

\subsection{DEMs}

DEMs data is 5 meters grid data measured by airborne laser survey (LiDAR) after earthquake. These data was combined the data measured by Miyagi Prefecture in March or April and by GSI in May or June, 2011.

\subsection{Land use}

Land use data is 100 meter grid data of National Land Information Data by the Ministry of Land, Infrastructure, Transportation and Tourism (MLIT). This data is divided into eleven categories, such as paddy, other farmland, forest, wasteland, building area, arterial traffic area, land for other use, rivers or lakes, seashore, seawater and golf course.

\subsection{Tsunami damage classification}

The authors divided tsunami damage into three categories by interpreting aerial photos; first rank (Rank 1) is the completely destroyed area where almost wooden buildings were lost, second rank (Rank 2) is the heavily damaged area where a large number of houses were destroyed by the tsunami, and third rank (Rank 3) is the flooded only area where houses were less destroyed. Figure 1 is tsunami damage classification map of a part of Sendai Plain where close to the Sendai Airport.

\subsection{Tsunami depth measured by MMS}

The tsunami flooded depth was measured by photogrammetric method using digital image taken by Mobile Mapping System (MMS).

Outline of MMS is shown in Figure 2. MMS obtains 360 degree panoramic image by cameras on a vehicle. IP-S2 by Topcon Corporation was used for this study, and the system is composed of 6 cameras, GPS antenna and IMU (inertial measurement unit). GPS antenna and IMU measure positions and tilts of cameras. Cameras can obtain image data at rates of 16 frames / second. Using this system, we obtain the image data with three dimensional location information. To select the position of tsunami flooded marks and ground surface in this image, it is possible to measure the tsunami flooded depth by calculation of image data (Figure 3 ).

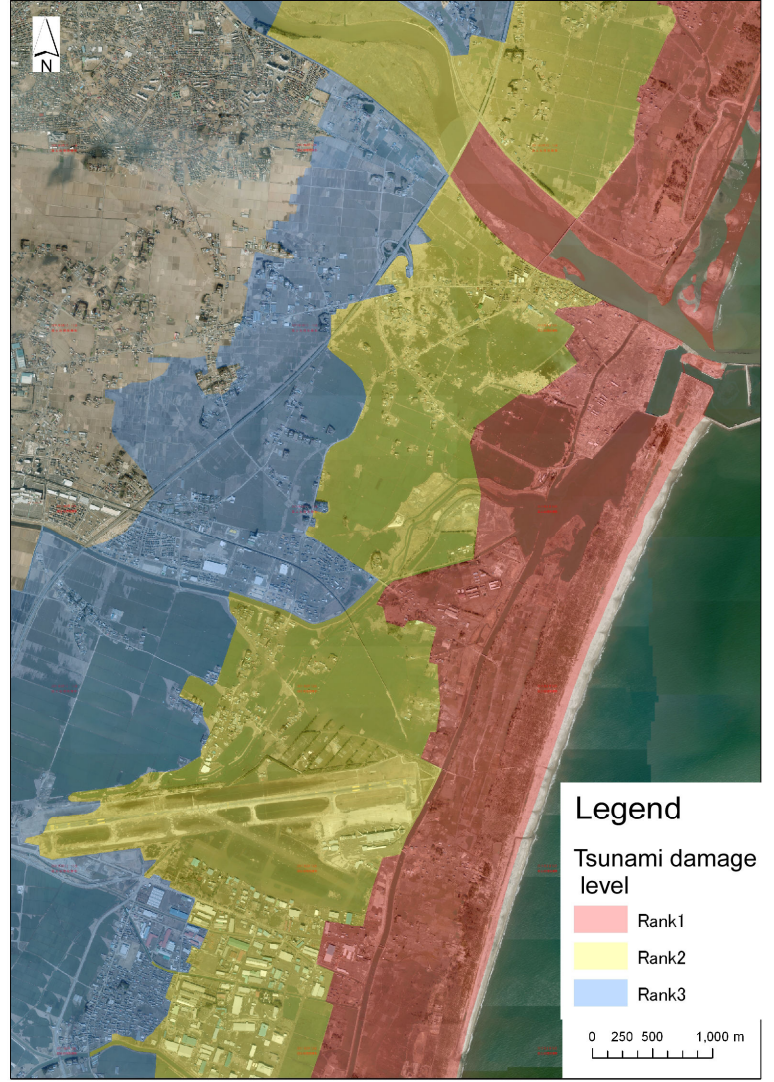

Figure 1. Tsunami damage map of Sendai Plain

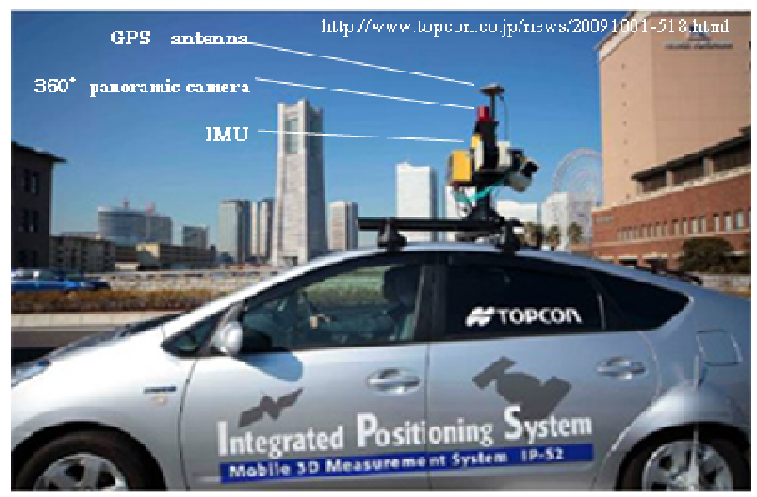

Figure 2. Outline of Mobile Mapping System (MMS)

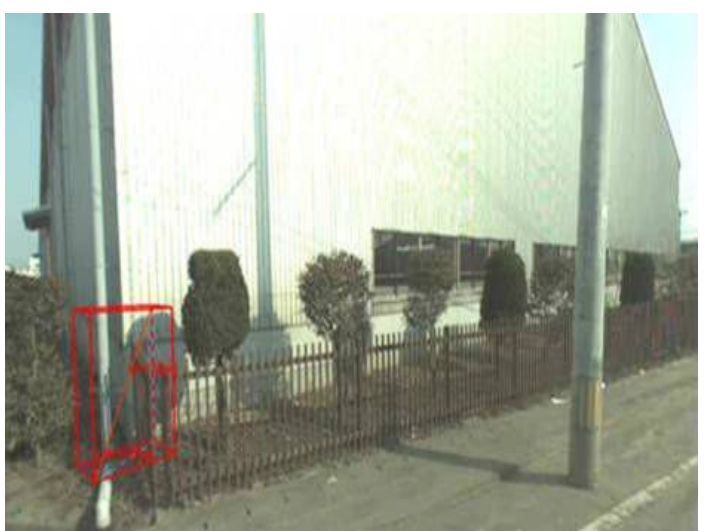

Figure 3. Measurement of tsunami flooded depth by MMS 


\section{RESULTS OF OVERLAY ANALYSIS}

\subsection{Relationship between tsunami damage and tsunami depth}

Figure 4 and 5 show overlay maps of tsunami damage level and tsunami flooded depth measured by MMS at Yuriage area, Natori City, Miyagi Prefecture and at the Sendai Airport area, Iwanuma City, Miyagi Prefecture, respectirely.

These figures show that the area with over $4 \mathrm{~m}$ tsunami flooded depth is equivalent to the rank 1 , and the area with over $1.5 \mathrm{~m}$ tsunami flooded depth is equivalent to rank 2 .

Figure 6 shows the distribution of tsunami flooded height measured by field survey results of the 2011 Tohoku Earthquake Tsunami Joint Survey Group (2011) and the authors' field survey and by MMS of GSI. Tsunami flooded height is calculated by the following formulas: Tsunami flooded height $=$ tsunami flooded depth + LiDAR DEM. The measurement results by MMS correspond well with the measurement results by field survey.

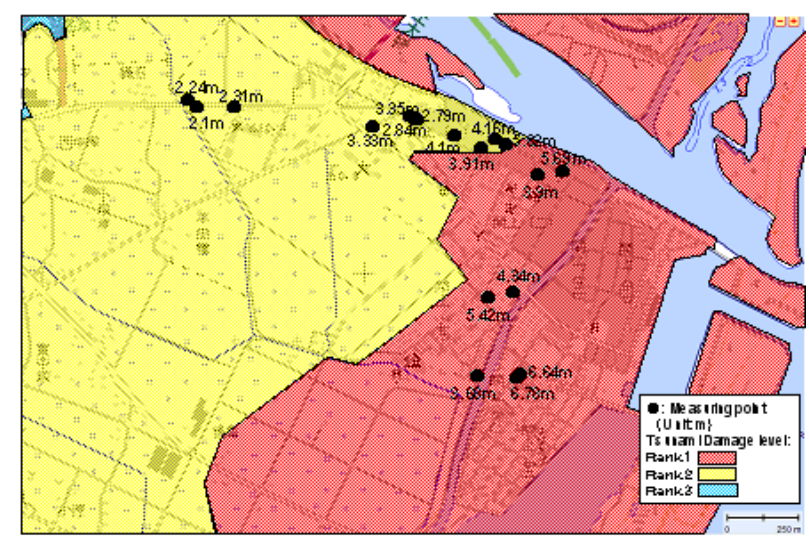

Figure 4. Tsunami flooded depth measured by MMS at Yuriage area (base map is Cyber Japan Web System)

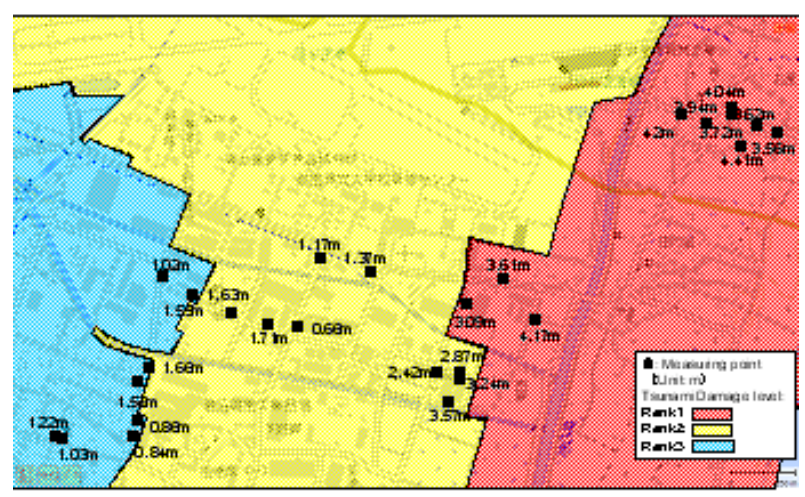

Figure 5. Tsunami flooded depth measured by MMS at Sendai Airport area

\subsection{Relationship between tsunami damage and geographic} condition such as landform, elevation and land use

The results of overlay analysis about geographic information and tsunami damage categories are shown in figure $7,8,9$. Figure 7 is overlay map of tsunami damage and landform classification. Figure8 is overlay map of tsunami damage and DEMs. Figure9 is overlay map of tsunami damage and land use.

In this section, we describe the outline of landform and land use in Sendai Plain using figure 7 and figure 9.
Landform within $1 \mathrm{~km}$ area from the coastline is mainly sand dune or sand bar with little higher elevation. Wide sand bars are dominate in the northern area from Abukuma River, but several narrow sand bars are dominate in the southern area from Abukuma River. Landform of inland area over $1 \mathrm{~km}$ from the coastline is coastal plain or delta. Valley plain or flood plain is dominated along Nanakita River, Natori River and Abukuma River. Natural levee and former river bed are only dominant along main large rivers.

Land use on sand dune or sand bar is forest, other farmland and building area. Forest is dominant in the northern area from Abukuma River, however, other farmland is dominant in the southern area from Abukuma River. Land use of inland area over $1 \mathrm{~km}$ from coastline is mainly paddy field. As building area and other farmland in inland area have zonal distribution along the coastline, these land use located on sand dune or sand bar in inland area.

The results of overlay analysis between tsunami damage level and other geographic information are as follows:

1) The completely destroyed area (Rank 1) was located within $1 \mathrm{~km}$ area from the coastline. Flooded depth of this area is over $4 \mathrm{~m}$, and landform classification of this area is almost sand dune or sand bar which has a little higher elevation compared with other area (Figure 7,8). Contrary to a poor relationship between tsunami damage and landform condition such as landform classification or elevation, there is a good relationship between area of tsunami damage rank 1 and distance from coastline.

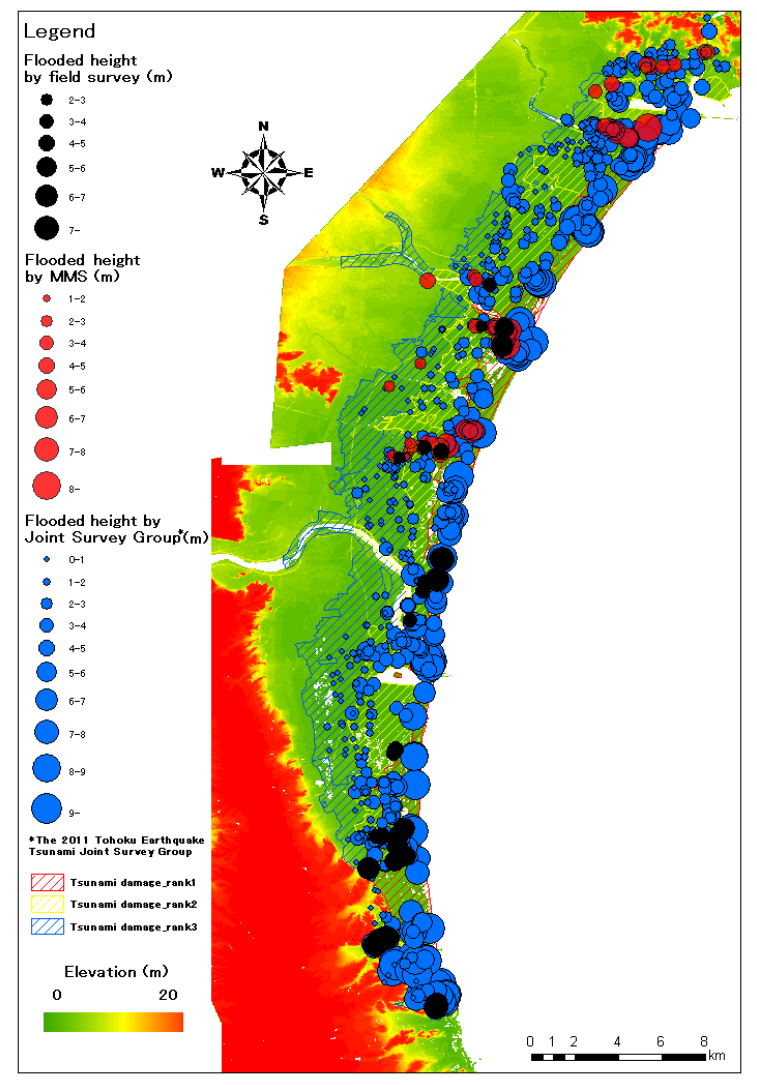

Figure 6. Distribution of tsunami flooded height measured by MMS and other research group 


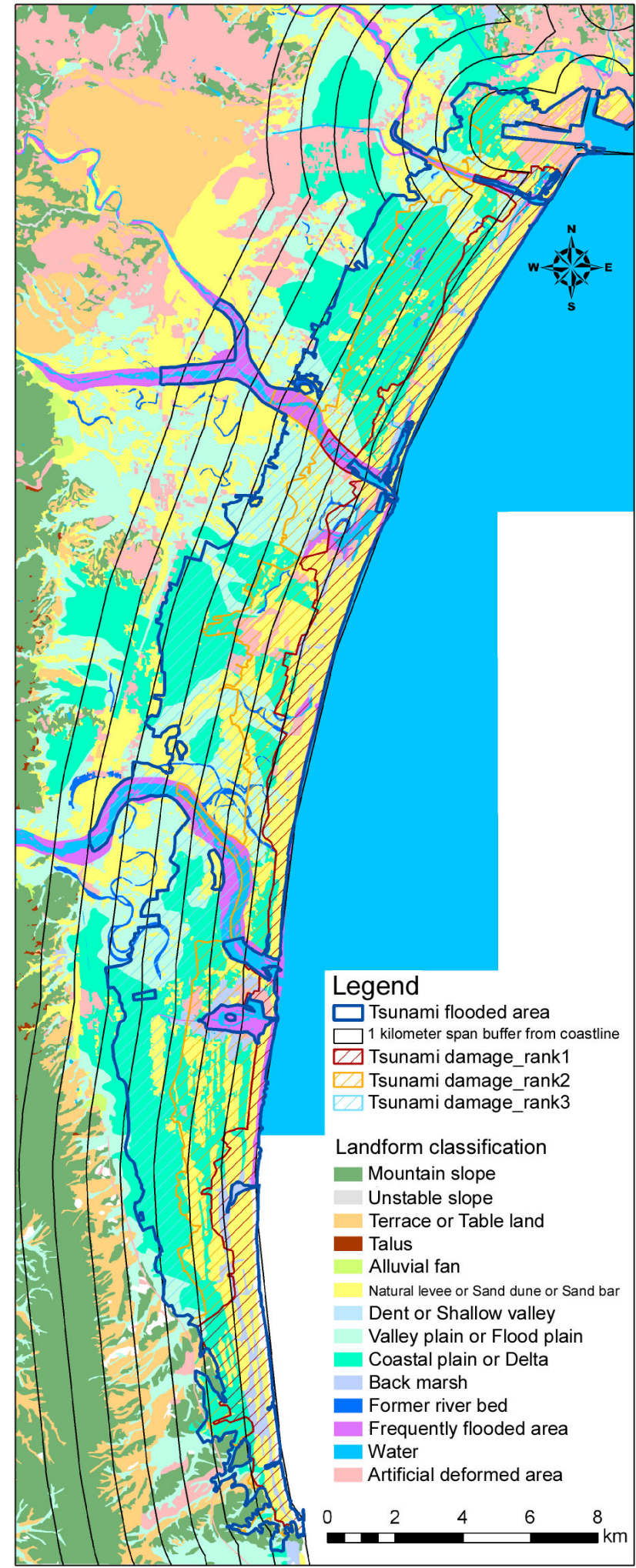

Figure 7. Overlay of tsunami damage and landform classification

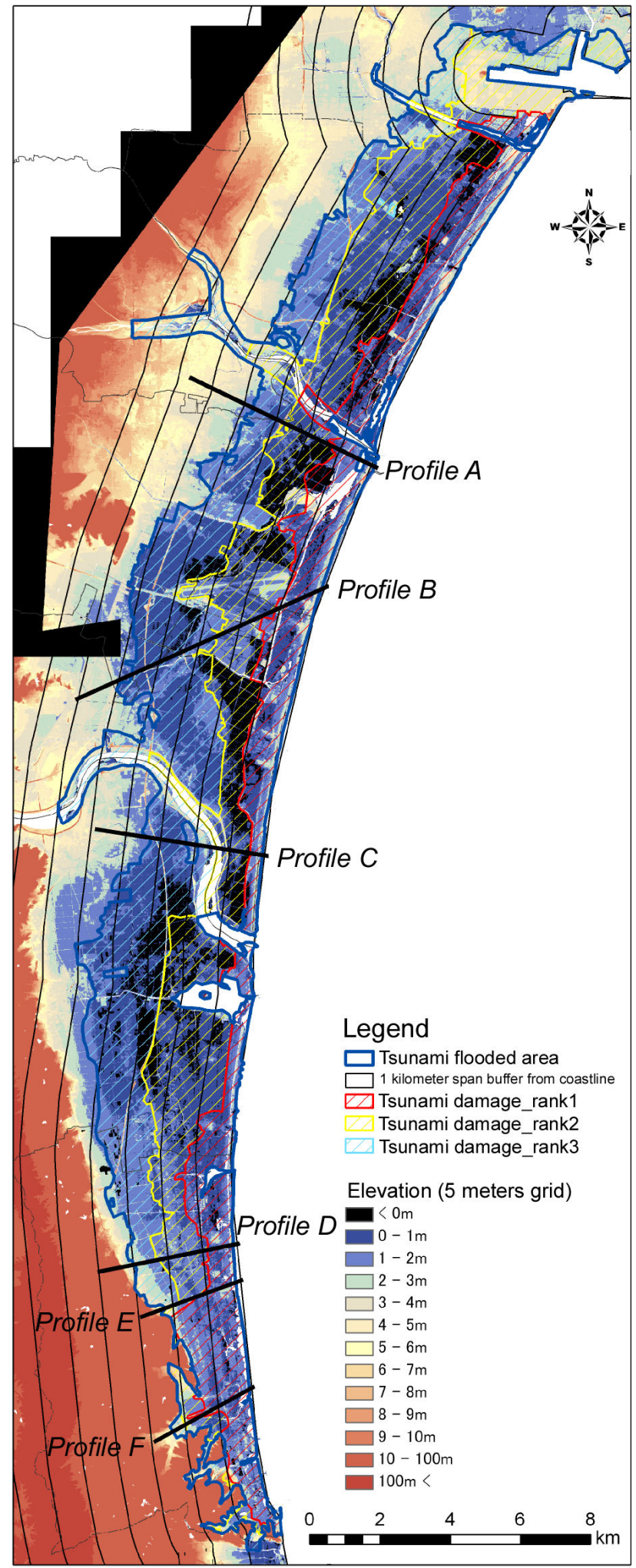

Figure 8. Overlay of tsunami damage and LiDAR DEM 


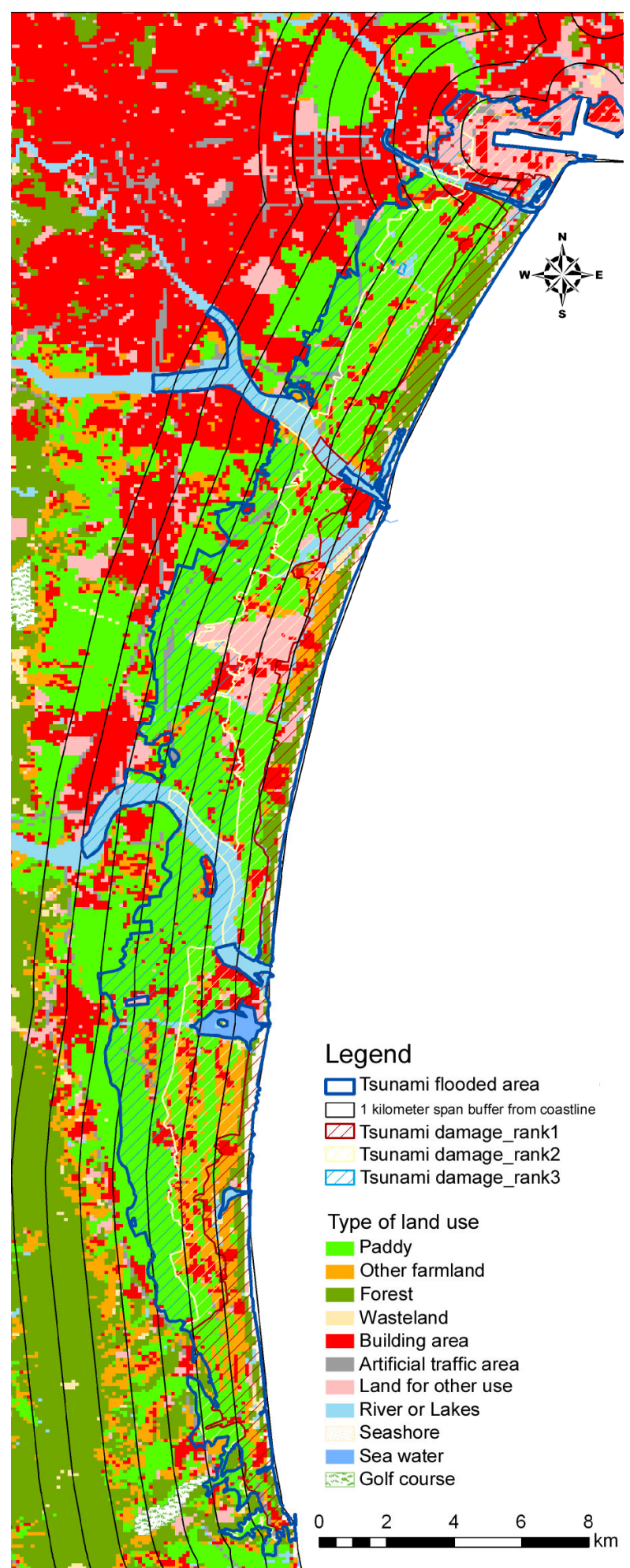

Figure 9. Overlay of tsunami damage and land use

2) The heavily damaged area (Rank 2) was observed up to 3 or $4 \mathrm{~km}$ from the coastline. Flooded depth of this area is over $1.5 \mathrm{~m}$, and the elevation of this area is less than $1 \mathrm{~m}$. There is a good relationship between location of damaged area of rank 2 and elevation.

3) The flood only area (Rank 3 ) was observed up to 4 or $5 \mathrm{~km}$ from coastline. Flooded depth of this area was less than $1.5 \mathrm{~m}$, and there is a good relationship between location of damaged area and landform classification. For instance, a certain area in valley plain and flooded plain was not affected by the tsunami, even though an area with almost the same height in coastal plain and delta was flooded.

\subsection{Relationship between tsunami damage and elevation on cross section}

For the discussion of relationship between tsunami damage level and landform condition such as flooded depth and elevation, we produced 6 cross sections of elevation of ground surface and tsunami flooded height along EW direction. The results are shown in figure $10,11,12,13,14$ and 15.

The area of tsunami damage level rank 1 is limited within $1 \mathrm{~km}$ area from the coastline. This area has a little higher elevation such as $1-3 \mathrm{~m}$, and flooded depth of this area is over $4 \mathrm{~m}$. Just after tsunami ran over a little higher landform such as sand dune or sand bar to lowland with $0 \mathrm{~m}$ elevation such as coastal plain or delta, the tsunami flooded height was decreased suddenly and the tsunami damage level was changed from rank 1 to rank 2 (figure 10,11).

On the north of the mouth of Abukuma River, the width of sand bar, which is about $500 \mathrm{~m}$, is narrower than other area. At the area of $500 \mathrm{~m}$ from the coastline, elevation of ground surface decreases from $2 \mathrm{~m}$ to $0 \mathrm{~m}$, and tsunami flooded depth also decreased from $5 \mathrm{~m}$ to $2 \mathrm{~m}$, and the tsunami damage level was changed from rank 1 to rank 2 (figure 12).

In the area close to JR Yamashita Station, the elevation of ground surface and tsunami flooded height are decreased suddenly from $2 \mathrm{~m}$ to $0 \mathrm{~m}$ and from $7 \mathrm{~m}$ to $3 \mathrm{~m}$ respectively at the position of $500 \mathrm{~m}$ from coastline, but tsunami damage level does not change (figure 13). The boundary line between rank 1 and rank 2 was located at $900 \mathrm{~m}$ from the coastline. We assumed the reason of difference of tsunami flood damage to another area is brought by the difference of land use and landform. Forest is dominant with wide width on sand bar in the northern area from Abukuma River, but other farmland is dominant with narrow width on sand bar in the southern area from Abukuma River. It may be presumable that difference of distribution of the completely destroyed area was brought by difference of roughness of ground surface, such as forest and other farmland.

In the southern part of Yamamoto Town, the boundary line between tsunami damage level rank 1 and rank 2 was located in $1.5 \mathrm{~km}$ from the coastline (figure 14, 15). We assumed the reason of difference of location of the boundary line is brought by the difference of elevation of sand dune or sand bar compared to another area. As the elevation of sand dune or sand bar in the southern Yamamoto Town is about $1 \mathrm{~m}$, the tsunami flooded height did not change just after tsunami run over sand dune or sand bar. The tsunami flooded depth was over $4 \mathrm{~m}$ at $1.5 \mathrm{~km}$ from the coastline, the tsunami damage level did not changed.

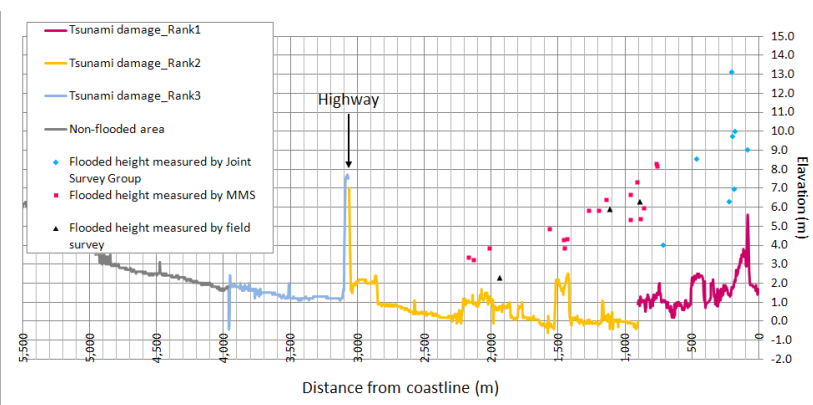

Figure 10. Cross section along EW direction of ground surface and tsunami flood depth on profile A (Yuriage, Natori City) 


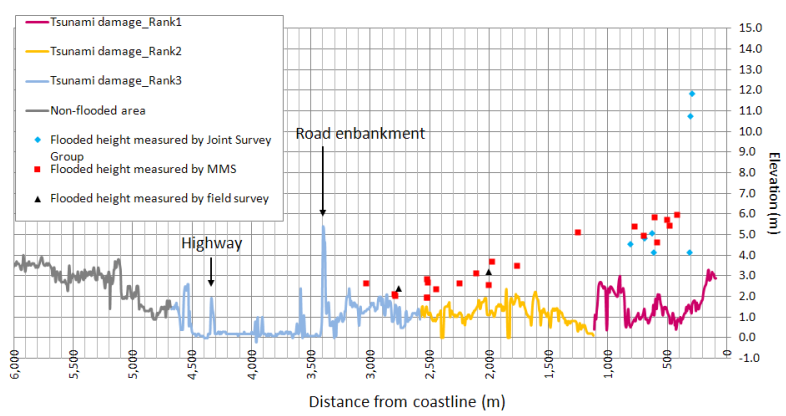

Figure 11. Cross section along EW direction of ground surface and tsunami flood depth on profile B (Sendai Airport, Iwanuma City)

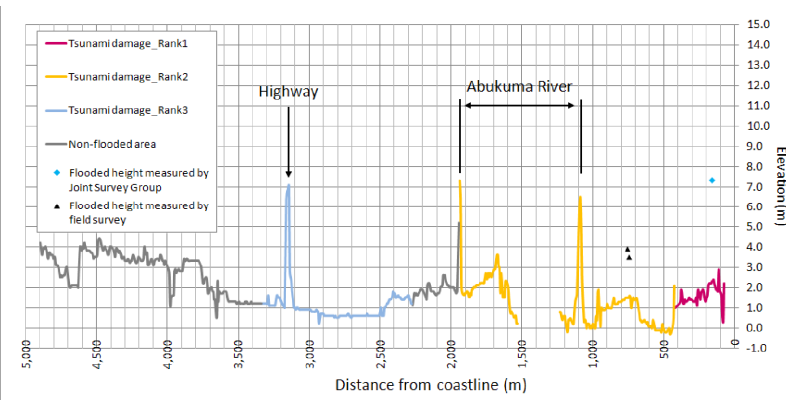

Figure 12. Cross section along EW direction of ground surface and tsunami flood depth on profile C (Mouth of Abukuma River, Iwanuma City and Watari Town)

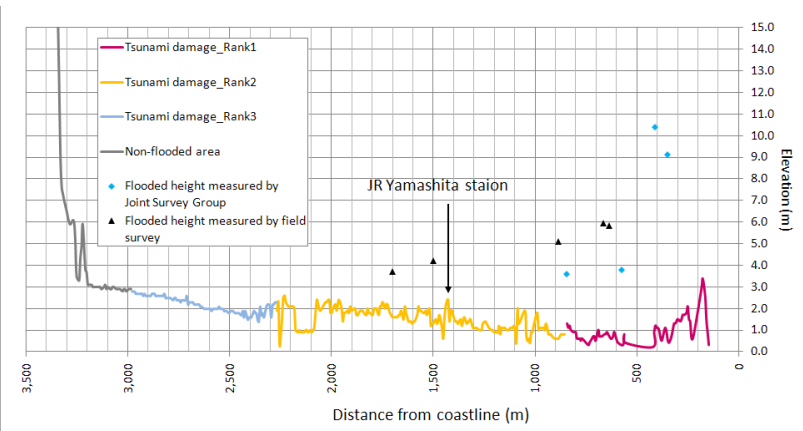

Figure 13. Cross section along EW direction of ground surface and tsunami flood depth on profile D (JR Yamashita Station, Yamamoto Town)

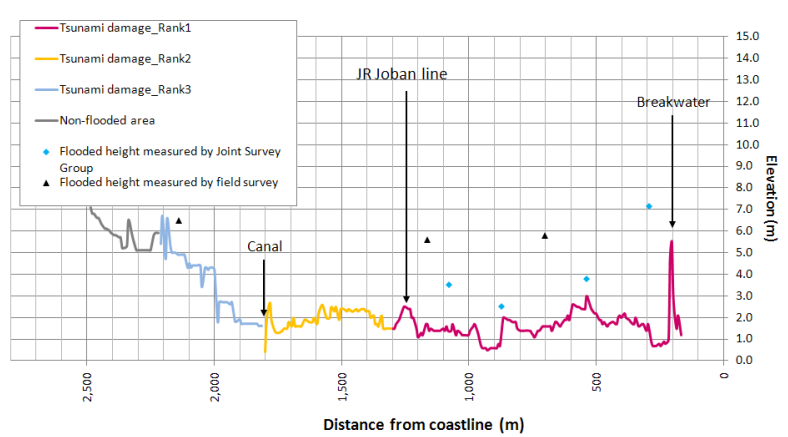

Figure 14. Cross section along EW direction of ground surface and tsunami flood depth on profile E (Takase, Yamamoto Town)

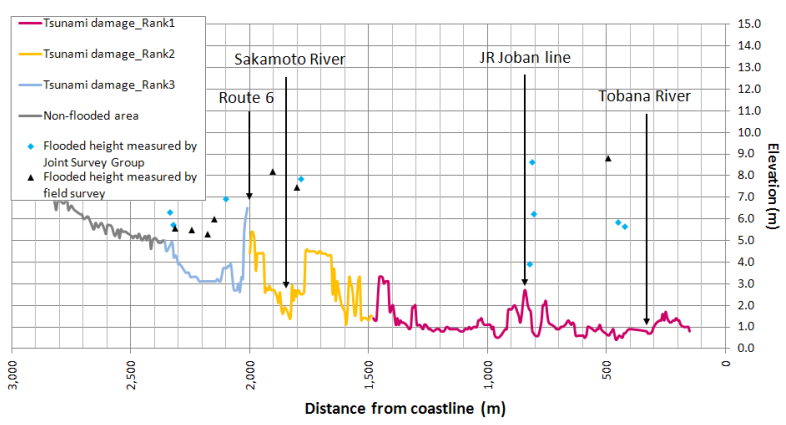

Figure 15. Cross section along EW direction of ground surface and tsunami flood depth on profile F (JR Sakamoto Station, Yamamoto Town)

\section{CONCLUSION}

The authors analyzed the relationship between tsunami flood damage by the Great Tohoku Earthquake and geographical condition in Sendai Plain. The completely destroyed area was located within $1 \mathrm{~km}$ area from the coastline, and tsunami flooded depth of this area is over $4 \mathrm{~m}$. The range of this area depends on the distance from the coastline. The heavily damaged area with over $1.5 \mathrm{~m}$ tsunami flooded depth was observed at the area with less than $1 \mathrm{~m}$ elevation up to 3 or $4 \mathrm{~km}$ from the coastline. The flood only area with less than $1.5 \mathrm{~m}$ tsunami flooded depth was observed the area with less than $2 \mathrm{~m}$ elevation up to 4 or $5 \mathrm{~km}$ from the coastline. There is a good relationship between tsunami flood damage level and tsunami flooded depth. Also, there is a good relationship between tsunami flooded area and elevation of ground surface. Certain area in valley plain and flood plain was not flooded by the tsunami, even though an area with almost the same height in coastal plain or delta was flooded. The difference of distance from the coastline in completely destroy area may be caused by roughness of land use. These results mean that it is important for tsunami disaster management to consider not only DEMs but also landform classification and land use.

\section{REFERENCE}

The 2011 Tohoku Earthquake Tsunami Joint Research Group, 2011. Tohoku Earthquake Tsunami Information, http://www.coastal.jp/ttjt/ (accessed 12 April 2012)

\section{ACKNOWLEDGEMENTS}

The part of this research is supported by Grants in Aid for Scientific Research (24240114). 